\title{
Correction to: Mapping the field of research on African higher education: a review of 6483 publications from 1980 to 2019
}

\section{Nelson Casimiro Zavale ${ }^{1,2}$ (D) Christian Schneijderberg ${ }^{2}$ (D)}

Published online: 8 July 2021

(c) Springer Nature B.V. 2021

\section{Correction to: Higher Education https://doi.org/10.1007/s10734-020-00649-5}

The original version of this article unfortunately contained a mistake. The presentation of Table 9 was incorrect. The correct Table 9 is now shown here.

The original article has been corrected.

The online version of the original article can be found at https://doi.org/10.1007/s10734-020-00649-5

Nelson Casimiro Zavale

nelson.casimiro.zavale@gmail.com; zavale@incher.uni-kassel.de

Christian Schneijderberg

schneijderberg@incher.uni-kassel.de

1 Eduardo Mondlane University, Av. Julius Nyerere 3453, Maputo, Mozambique

2 International Centre for Higher Education Research (INCHER), University of Kassel, Mönchebergstr. 17, 34109 Kassel, Germany 


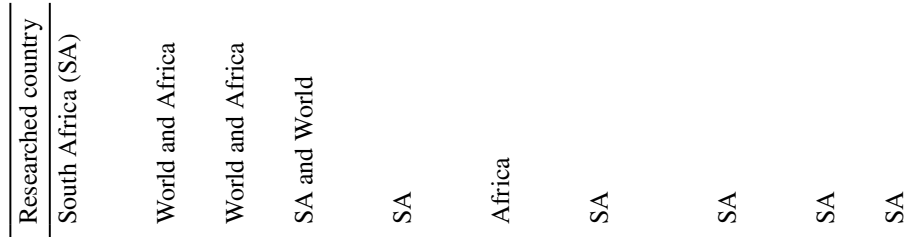

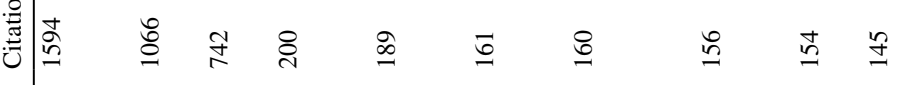

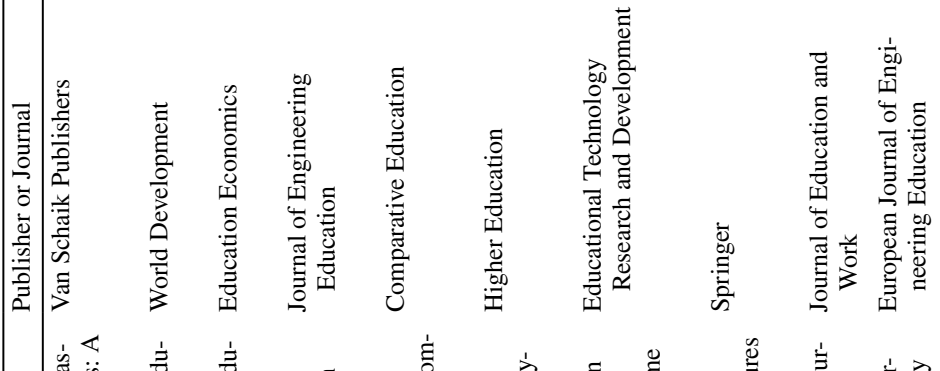

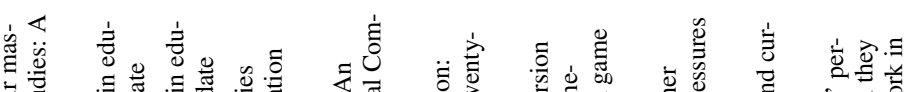

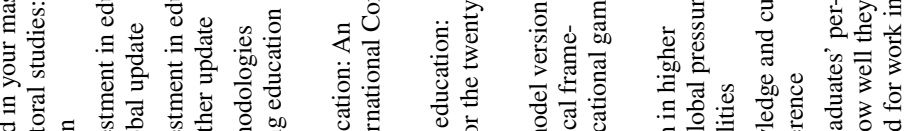

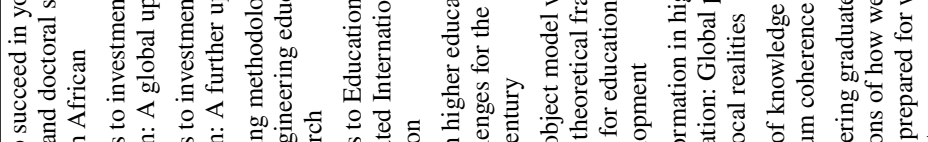

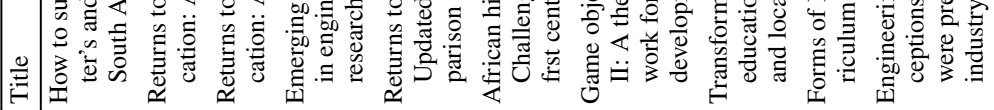

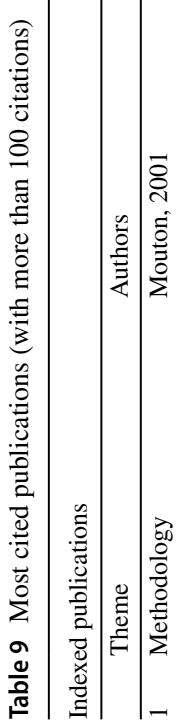

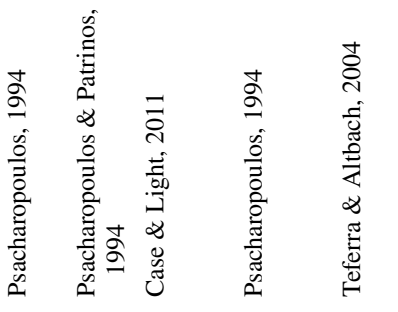

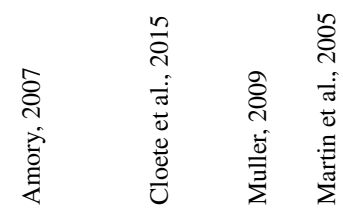

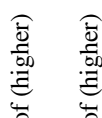

苍苍

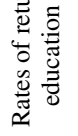

焉

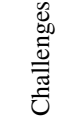

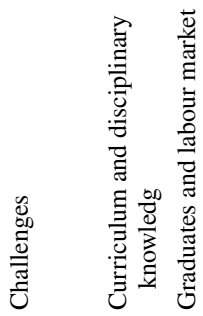

Springer 


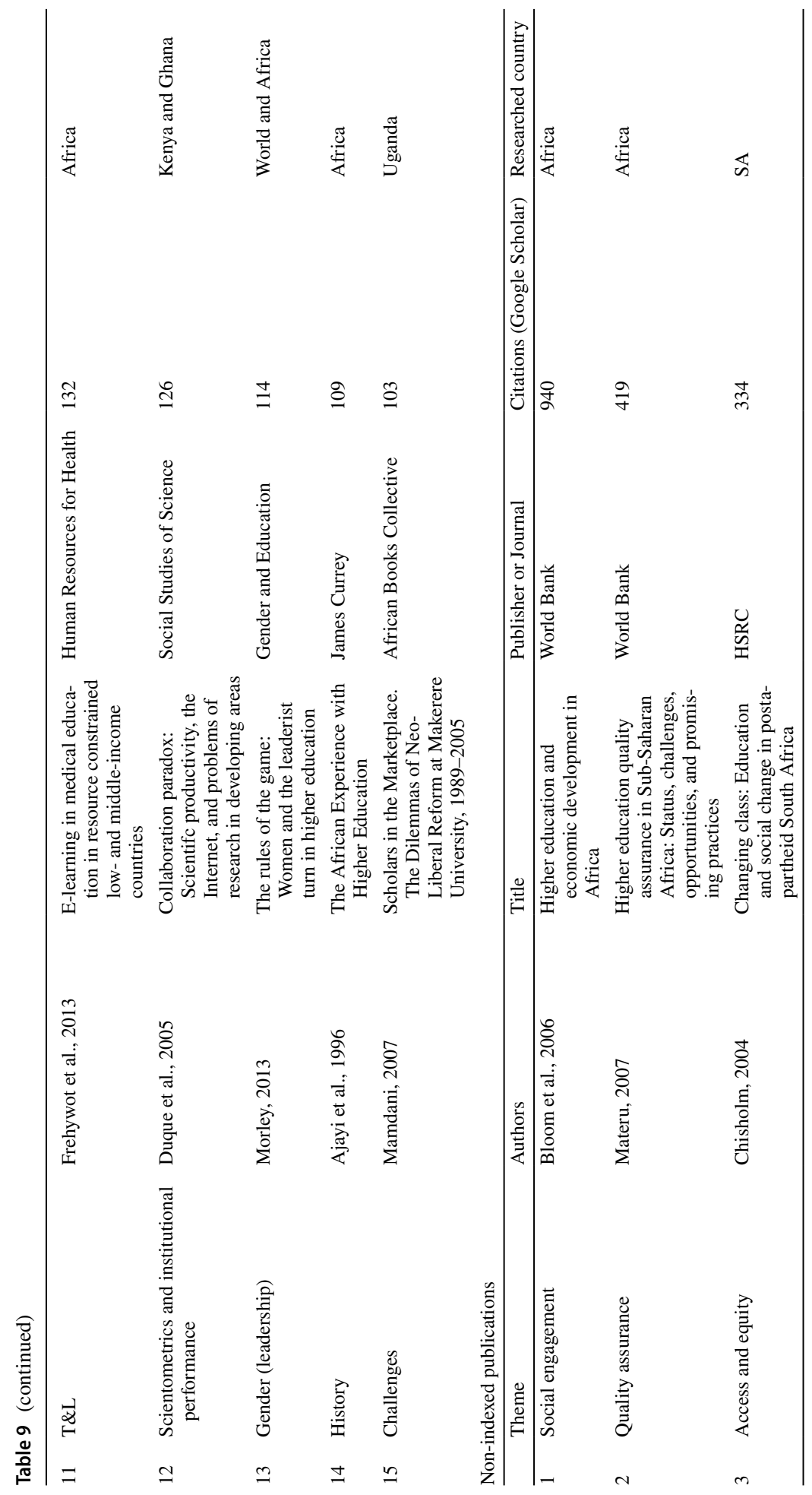




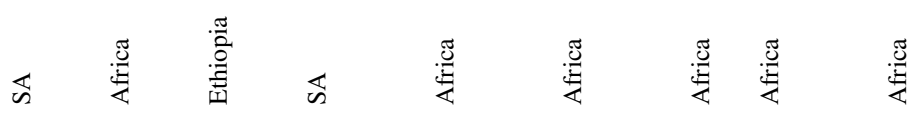

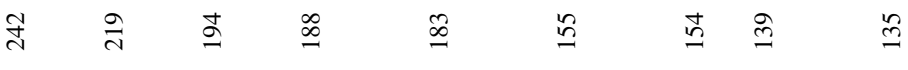

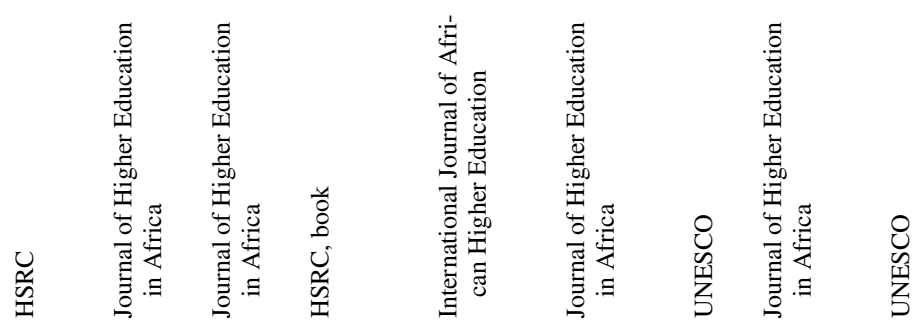

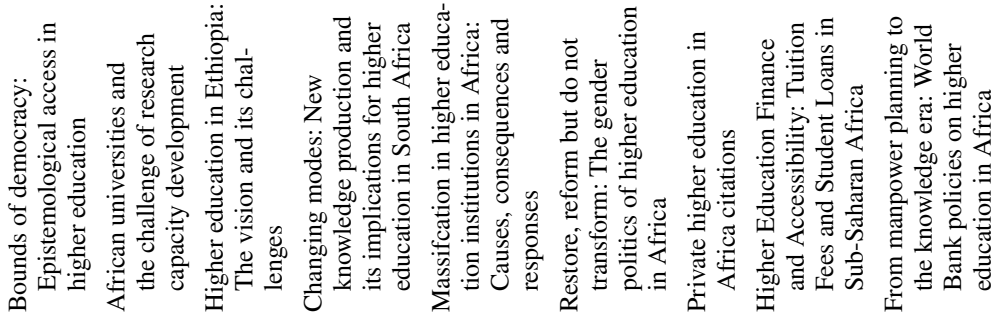

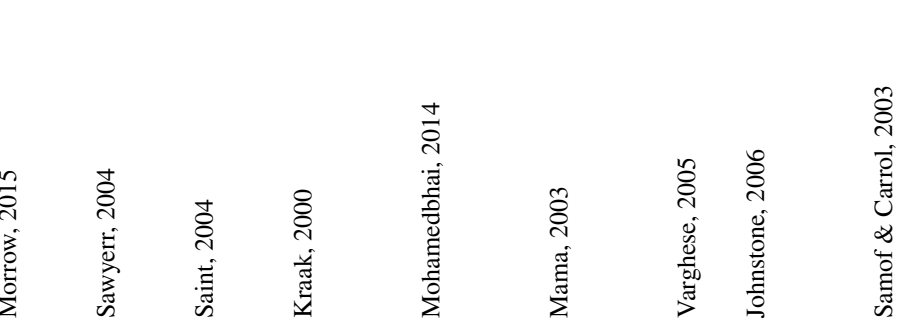

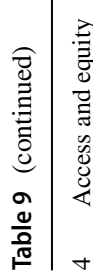




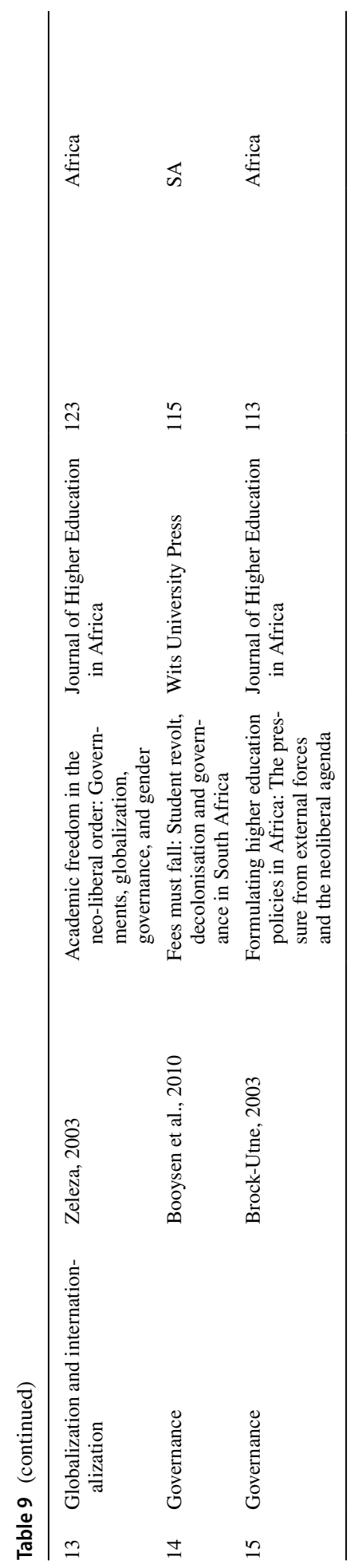


Publisher's Note Springer Nature remains neutral with regard to jurisdictional claims in published maps and institutional affiliations. 